American Journal of Pharmaceutical Education 2019; 83 (9) Article 6237.

\title{
RESEARCH
}

\section{Implementation of an ACPE-Accredited PharmD Curriculum at a Saudi College of Pharmacy}

\author{
Abdulmalik M. Alkatheri, PharmD, ${ }^{\mathrm{a}, \mathrm{b}}$ Abdelkareem M. Albekairy, PharmD, MSc, a,b \\ Nabil Khalidi, PharmD, ${ }^{\mathrm{a}, \mathrm{c}}$ Stephanie J. Phelps, PharmD, ${ }^{\mathrm{d}}$ Dick R. Gourley, PharmD, \\ Majed Al Jeraisy, PharmD, MSc, MEd, ${ }^{\mathrm{a}, \mathrm{b}}$ Amjad M. Qandil, PhD ${ }^{\mathrm{a}, \mathrm{b}}$ \\ ${ }^{a}$ King Saud bin Abdulaziz University for Health Sciences, College of Pharmacy, Riyadh, Saudi Arabia \\ ${ }^{\mathrm{b}}$ King Abdulaziz Medical City, Ministry of National Guard Health Affairs, Riyadh, Saudi Arabia \\ ${ }^{\mathrm{c}}$ University of Michigan College of Pharmacy, Ann Arbor, Michigan \\ ${ }^{d}$ The University of Tennessee Health Science Center College of Pharmacy, Memphis, Tennessee \\ ${ }^{\mathrm{e}}$ The University of Tennessee Health Science Center Research Foundation, Knoxville, Tennessee
}

Submitted December 21, 2016; accepted February 28, 2019; published November 2019.

Objective. To establish an academic curricular collaboration between the newly established college of pharmacy at King Saud Bin Abdulaziz Saudi University for Health Sciences (KSAU-HS) and a US college of pharmacy accredited by the Accreditation Council for Pharmacy Education, and assess measures of success.

Methods. Criteria for selecting a college for collaboration were established. A systematic approach was followed in negotiating legal, logistical, and financial issues with the selected collaborating institution. Course materials were transferred and implemented and minimal changes were made to the alignment and sequencing of lectures. The faculty at KSAU-HS developed and implemented research and seminar courses. Pharmacy practice experiences were designed and rubrics were developed.

Results. All courses were implemented successfully. The PharmD students scored significantly higher in all academic levels in a benchmarked progress test than did students in other programs. Students' evaluation of 43 first-, second-, and third-year courses in 2017-2018 using a survey that assessed numerous aspects of each course showed significantly higher overall satisfaction than the institutional averages. Also, female students indicated significantly higher satisfaction with the PharmD program than did male students.

Conclusion. The transfer and implementation of an accredited PharmD curriculum to the KSAU-HS College of Pharmacy went smoothly and the program was launched on time. Learning and teaching success was facilitated by the KSAU-HS faculty. Program outcomes were verified by students' high scores on a benchmarked examination and by their satisfaction with the courses.

Keywords: curriculum implementation, collaboration, PharmD program, curriculum development, ACPEaccredited program

\section{INTRODUCTION}

In Saudi Arabia, the ratio of pharmacists in the public sector to the patient population is only 0.13 per $1000,{ }^{1}$ which is seven times less than in the United States (1.01 pharmacists per 1000 people). ${ }^{2}$ To render pharmaceutical care to its population and to facilitate the launching of health care initiatives, the country had to resort to multiple

Corresponding Author: Abdulmalik M. Alkatheri, Pharmacy Practice Department, College of Pharmacy, King Saud bin Abdulaziz University for Health Sciences, Ministry of National Guard Health Affairs, Riyadh 11481, Saudi Arabia. Tel: +966 11 4295005. Fax: +966114295057. Email: katheria@ngha.med.sa. strategies to increase its human professional resources. These strategies included contracting foreign health care providers and educators to supplement the pharmacist workforce; offering pharmacy scholarship programs to Saudi students to study abroad in pursuit of undergraduate and postgraduate training; and expanding enrollment in postgraduate pharmacy residency training programs accredited by the American Society of Health-System Pharmacists (ASHP). However, the long turnaround time for graduates to return to Saudi Arabia, the limited number of locally trained graduates, the high turnover of foreign-contracted clinical pharmacists, and certainly the difficulty, cost, and time spent in recruiting replacement 


\section{American Journal of Pharmaceutical Education 2019; 83 (9) Article 6237.}

workers has driven the fast creation of institutions of higher education. ${ }^{3}$ Many of these new institutions have sought international collaborations to facilitate speedy and quality implementation of educational programs. King Saud bin Abdulaziz University for Health Sciences (KSAU-HS) in Riyadh was among those that favored this pathway.

With the recent successful outcomes in global health research and intervention, a new attitude of international cooperation has emerged amid the diverse professional and academic entities in developed and developing countries. ${ }^{4,5}$ What may have started as health aids and missions of health care volunteers, selected collaborative research, and international medical intervention by government and nongovernment agencies has now expanded to encompass formal collaborative agreements in research, teaching, training, and intervention. ${ }^{6}$

A prime example of such cooperation is the establishment of the United States-Thai Consortium between eight Thai schools of pharmacy and nine US colleges. The major goal of the consortium was expanding colleges of pharmacy in Thailand through training of new faculty members, a program that was planned to last until 2022 .

The KSAU-HS was established in 2005 within the campus of the King Abdulaziz Medical City (KAMC), Ministry of National Guard Health Affairs (MNG-HA) in Riyadh. Beginning with academic year 2013-2014, a state-of-the-art university campus which includes the colleges of medicine, dentistry, pharmacy, nursing, public health and health informatics, applied medical sciences, science and health professions was commissioned. This campus is across the street from the Medical City, which houses a 1250 operational beds tertiary care facility accredited by the Joint Commission International. Plans to establish a college of pharmacy were announced in 2010. The college officially admitted its first class of students in 2012 to fulfil the institution's mission of providing “. . .high quality health sciences education, health-related research, and community services that promote the health of society" and vision which is "to achieve global leadership in health professions education, with commitment to excellence in research, patient care, and community service."

Following the announcement to establish the college of pharmacy, there was a consensus from University and College Administration to acquire the Doctor of Pharmacy (PharmD) curriculum from a relatively high-ranking college of pharmacy in the United States that was accredited by the Accreditation Council for Pharmacy Education (ACPE). This direction was in line with the desire among pharmacy academicians at KSAU-HS to implement a curriculum that was patient-centered and clinically focused ${ }^{8}$ to produce competent pharmacists who could supplement the limited supply of locally trained pharmaceutical care providers. ${ }^{3,9}$ Clearly, in terms of academic and practice components, pharmacy schools share similar global challenges in meeting societal needs and individual professional aspirations. ${ }^{10}$ Thus, acquiring an American curriculum through a collaborative agreement with an ACPE-accredited program was quite attractive, although examples of such collaborations with internationally established schools of pharmacy were relatively limited. ${ }^{11}$

Such curricular acquisition would give the newly established college of pharmacy the advantage of implementing an already established curriculum. However, the curriculum would require limited but necessary modifications and improvements to reflect the country and its culture in areas related to pharmacy administration and pharmacy law. Specifically, changes would be needed to accommodate Saudi Arabian laws regulating health care and health services provision, as well as medication therapy management and training at sites such as ambulatory care and community pharmacies to accommodate cultural issues and concerns. ${ }^{12}$ This PharmD program serve to graduate competent clinical practitioners who would be capable of meeting the challenges of a rapidly expanding health care system. Moreover, under this time-limited collaborative agreement, the KSAU-HS College would continue to implement the ACPE-accredited program while it was planning its own research and teaching innovations. The new college capitalized on the advantage of affiliating the clinical pharmacists and residents of the MNG-HA Hospitals located on campus with its teaching program. The postgraduate residency program at MNG-HA received the American Society of Health-System Pharmacists (ASHP) accreditation in 2013. This paper discusses the process of establishing and assessing a curricular collaboration between the College of Pharmacy at KSAU-HS and an ACPE-accredited college of pharmacy in the United States.

\section{METHODS}

The KSAU-HS announced the establishment of the College of Pharmacy in 2010. To accomplish this, a steering committee of 10 academicians and practitioners was established. Seven of the committee members were senior US-trained clinical pharmacists who had academic appointments in the college of medicine, and three nonpharmacy faculty members, each of which was a chairperson of a department in the College of Medicine: medical education, basic medical sciences, and basic sciences. The committee was charged with planning the launch of the college of pharmacy on the KSAU-HS 


\section{American Journal of Pharmaceutical Education 2019; 83 (9) Article 6237.}

campus within two years. The task was to seek a reputable and accredited PharmD program, preferably from the United States, that would meet the needs and expectations of KSAU-HS. Once identified, negotiations with that program were to begin, with a goal of submitting a comprehensive PharmD program proposal to the university administration.

The committee began by formulating a list of 12 criteria with which to rank the colleges it intended to negotiate with (Table 1). The criteria and the weight assigned to each criterion was commensurate with KSAU-HS College of Pharmacy's needs assessment and priorities set by the steering committee.

The process of choosing a program occurred in three stages. In stage 1 , the criteria were used as a rubric by the steering committee to evaluate the 25 colleges being considered (Table 1). Exclusion criteria was scoring less than $50 \%$ on the rubric or already having some sort of collaboration with one or more other Saudi universities.

In stage 2, a written communication was sent to the selected universities, inquiring about the feasibility of future collaboration. To assist the US universities in considering the proposed collaboration, information about KSAU-HS, including size and nature of the

Table 1. Criteria Used by a Saudi College of Pharmacy for Selecting a US College of Pharmacy with Which to Collaborate on Using Their Accredited Doctor of Pharmacy Curriculum

\begin{tabular}{lc}
\hline Criteria & Weight (\%) \\
\hline $\begin{array}{l}\text { Credibility and reputation of the university and } \\
\text { school of pharmacy to be approached }\end{array}$ & 15 \\
Collaboration experience with other institutions & 10 \\
Willingness to negotiate and assist & 15 \\
Utilization of Problem Based Learning (PBL) in & 10 \\
the curriculum & 5 \\
Presence of detailed written curriculum \\
$\begin{array}{l}\text { Transferability of the curriculum from the host } \\
\text { school, eg presence of web-based curriculum }\end{array}$ \\
$\begin{array}{l}\text { Compatibility of the considered curriculum } \\
\text { with KSAU-HS mission, vision, values and }\end{array}$ \\
$\begin{array}{l}\text { competencies } \\
\text { Curriculum requirements matches KSAU-HS } \\
\text { available and potential resources }\end{array}$ \\
$\begin{array}{l}\text { Innovation in teaching and practical experience } \\
\text { eg, Skills Lab and early clinical exposure, etc. }\end{array}$ \\
$\begin{array}{l}\text { Opportunities for faculty development if needed } \\
\text { Track record in curriculum development and } \\
\text { revision }\end{array}$ \\
$\begin{array}{l}\text { Accreditation status of the candidate school and } \\
\text { its national and international recognition for } \\
\text { program and its faculty }\end{array}$ \\
\hline
\end{tabular}

institution, mission, vision, and supporting facilities (especially affiliated hospitals), was furnished to each institution. After stage 2, a list of 10 potential universities was produced, but two them were eliminated due to limited success of Problem Based Learning (PBL) in their curricula based on the steering committee analysis resulting in a list of eight candidates.

In stage 3, a dialogue was initiated with those eight institutions to receive collaboration proposals that focused on matters pertaining to curriculum licensing, access to curriculum software and PowerPoint files, use of established syllabi and examination banks, assistance with faculty enhancement activities, exchange programs, clinical workshop offerings, accepting qualified students in academic postgraduate and professional training programs, and desirability to conduct collaborative research in areas of strength and societal need in Saudi Arabia.

Some schools had concerns related to intellectual property of the curriculum, while others were deterred by the cost and complexity of transferring the curriculum.

After a direct dialogue with the five shortlisted institutions and review of the outcomes of these dialogs, it was finally decided that the University of Tennessee Health Science Center (UTHSC) was the most suitable candidate for collaboration.

After completing the three-stage process, KSAU-HS chose to collaborate the PharmD program at the UTHSC. A delegation composed of the steering committee chair and two selected pharmacy practitioners was authorized by KSAU-HS administration to conduct a site visit to the University of Tennessee and to negotiate the terms of a contract, including financial compensation. Over a fourday period in March 2011, the delegates met with UTHSC campus administration and UTHSC College of Pharmacy leadership, had discussions with various course coordinators and faculty members, and visited applicable college sites.

Several sessions were held to educate UTHSC faculty in the College of Pharmacy and Department of Pharmacology in the College of Medicine about the collaborative agreement and opportunities to participate. A written release was created and approved by UTHSC and the University of Tennessee. All faculty members wishing to participate were required to sign the release. All but two faculty members agreed to participate, an issue that was resolved internally by UTHSC. The US copyright laws posed an even greater challenge. It was feasible and permissible for our faculty members to use images in their lectures that would be taken from course textbooks. Similarly, images available on US government sites were also acceptable for use provided the source was cited. At times it was extremely difficult to identify who owned the 


\section{American Journal of Pharmaceutical Education 2019; 83 (9) Article 6237.}

copyright to a particular image. This was especially true if the image randomly appeared on the internet without a citation. To address these gaps UTHSC hired a graphics designer who worked with faculty members to create original images for use in lectures. Once these details were addressed, a memorandum of understanding was signed, which authorized the KSAU-HS College of Pharmacy to acquire the programs and resources listed in Table 2.

The KSAU-HS attempted to use an international courier to transfer large amounts of materials via a thumb drive, but security issues and delivery logistics caused persistent delays in the delivery of materials. Alternatively, a shared Dropbox business account was established to facilitate the transfer of large size curricular files and images (Dropbox, San Francisco, CA).

Content experts reviewed the courses received from UTHSC to perform limited but absolutely necessary changes to ensure that the course material was up to date, and that lectures were properly sequenced and aligned between courses with minimum redundancy. In addition, few new courses (eight credit hours) and experiential training courses that were outside the agreement with UTHSC were completely designed by KSAU-HS content experts.

Once courses were taught for the first time using the approach of and materials from the UTHSC College of Pharmacy, KSAU faculty members were asked to respond to a 17-item questionnaire assessing their experience and students' responses to the courses taught. Faculty

Table 2. Content of the Transferred Curriculum Content of the Accredited Doctor of Pharmacy Curriculum From the University of Tennessee Health Science Center Adapted by the King Saud bin Abdulaziz University for Health Sciences in Riyadh

Course syllabi (required and electives), handouts, and suggested and/or required reading material

Educational goals and objectives

PowerPoint files for all lectures

All non-media site videos

Media site video of UTHSC faculty lectures (pending approval by faculty)

Examination bank and answer keys

Access to the licensed courses in UTHSC Blackboard

Recitations and laboratory assignments and accompanying material

Pharmacy compounding lab requirements

Allocation of 3-5 positions for selected Saudi scholarship students for PharmD, PhD, residency, or fellowship programs once they pass scrutiny by KSAU-HS and UTHSC recommendations were then included in new course books, and proposals for adding, deleting, revising, and resequencing lectures had to be justified on a form especially designed for this purpose. These requests had to be reviewed by the Curriculum Committee and approved by the College Council to be implemented.

The success of the collaboration was assessed based on the performance of KSAU PharmD students on an externally benchmarked progress test administered in academic year 2017-2018. The progress test consisted of 100 multiple-choice questions (MCQs) and was constructed by faculty members from three national PharmD programs, including KSAU-HS, and administered to students in professional years 1 through 4 (PY1-PY4) in these programs. Two other programs that were used as external benchmarks included one PharmD program that was nationally accredited and another that was internationally accredited. The examination evaluates the progress of pharmacy students' knowledge and abilities from one academic level to the next. Each of the MCQs was worth one point and covered the various disciplines of pharmacy (27\% pharmaceutical sciences and 73\% pharmacy practice).

Students' course evaluation surveys provide an indirect measure of collaboration success. KSAU-HS distributes standardized course evaluation surveys, which students are required to fill for every course they complete. In addition to questions on demographics, each survey contained 24 positively stated items that assessed numerous aspects of the course and were rated on a fivepoint Likert scale on which $5=$ strongly agree, $4=$ agree, $3=$ neutral, $2=$ disagree, and $1=$ strongly disagree, with higher scores indicating more favorable responses. The 24-item survey instrument was divided into four parts, which pertained to the beginning of the course (preparation), what happened during the course (delivery), perceived impact on student development, and overall course evaluation, respectively.

Descriptive and univariate statistical analyses of student grades in the externally benchmarked progress test and student satisfaction scores on course evaluations were performed using one-way ANOVA and $t$ tests. All statistical analyses were performed using SPSS 21.0 (IBM, Chicago, IL).

\section{RESULTS}

The delegation authorized by the KSAU-HS administration to negotiate the terms of a contract including financial compensation was faced with concerns raised by UTHSC faculty members related to intellectual property and ownership of their respective educational materials. While UTHSC administration was also concerned about 


\section{American Journal of Pharmaceutical Education 2019; 83 (9) Article 6237.}

this item, they were most interested in the protection of the UTHSC brand and adherence to US copyright protection of items that would be provided. It was clear from UTHSC policy that all intellectual property related to education were owned by the faculty member who created that content.

Course materials were transferred sequentially into the business Dropbox starting with materials for the first professional year curriculum, and were provided one year in advance of the time the course would be taught. The transferred material included the curriculum plan; course descriptions; course syllabi, including lecture topics and schedules; PowerPoint presentations of lectures; and an examination bank. The UTHSC College of Pharmacy also provided a variety of electives that were selected by KSAU as subjects of interest. Clinical pharmacy faculty members who were graduates and trainees of the US educational system and were also experienced practitioners at the Ministry of National Guard Health Affairs (MNGHA), along with select pharmaceutical sciences academicians, were positioned to receive, coordinate, and teach the transferred courses. Courses were coded according to the KSAU-HS system into the curriculum plan, and the study plan was submitted for approval by the KSAU-HS University Council (Appendix 1). With the approval of the proposed study plan, experienced faculty members were assigned as course coordinators and were asked to examine the material, especially to ensure that it was upto-date with regard to clinical guidelines and any new emerging drug therapy. Course books (course syllabi) were designed by course coordinators, then reviewed by the college curriculum committee and submitted for approval by the College Council one semester before the course was to be delivered. Course lectures were modified if needed to include new developments in the field. In addition, the Saudi health care system, the KSAU-HS preprofessional curriculum, and the local culture influenced the lectures' modifications. Students' assessment plan was developed immediately upon the receipt of the curriculum. Course by course rubrics were designed for appraising student performance in non-examination sessions and were included in the corresponding course books. The UTHSC examination bank was not used as there was a genuine desire in the KSAU-HS College of Pharmacy for faculty members to prepare their own examination questions that reflected the class activities in the environment in which the students were taught.

Meanwhile, senior members of the implementation team at KSAU-HS College of Pharmacy met monthly via video conferencing with the senior UT College of Pharmacy in charge of the curriculum transfer for consultation and follow up and to discuss items related to the agreement. About a year into the agreement, UTHCS released new student learning outcomes, which were provided to the KSAU-HS College of Pharmacy.

Specific courses were modified prior to implementation at KSAU-HS. Medicinal chemistry lectures were aligned with pharmacology lectures. Additionally, therapeutics courses lectures were re-sequenced and redundancies were eliminated. All therapeutic courses were taught onsite and assessed by KSAU-HS clinical pharmacy faculty members who were graduates of ACPEaccredited educational systems and who had completed at least one or two years of postgraduate training in accredited residency programs and/or fellowships. Select UTHSC faculty members were also invited to deliver several therapeutics lectures and write examination questions on the material they taught. Once the program was fully operational, meetings were held on an as needed basis. Clinical Toxicology, which was an elective course in the UTHSC PharmD curriculum, was implemented at KSAU-HS as a mandatory course. Introductory and advanced pharmacy practice experiences (IPPE and APPE; 51 credit hours), which were outside the agreement, were fully designed by KSAU-HS, while the placement of experiential experiences courses within the curriculum and their objectives were in harmony with UTHSC's PharmD curriculum as well as ACPE requirements. Finally, five new courses were added, namely Research Proposal, PharmD Research, Pharmacy Law, Immunizations, and a seminar course, all of which totaled eight credit hours. Post-implementation, more changes were made and reviewed thoroughly by the College of Pharmacy Curriculum Committee and then approved and endorsed by the College Council. The course's iterations from one year to the next were documented in a course history form, which was developed in house. Appendix 2 shows the course history form for Medicinal Chemistry I (PHBS 303), which was prepared by course coordinators to provide an overview of the changes made to the course's theme, delivery methods, and assessment. All changes were explained and justified in an accompanying document, and were discussed in the department council, reviewed by the Curriculum Committee, and approved by the College Council. This form was a valuable tool for instructors, curriculum managers, and accreditors to visualize the course's evolution form one year to another without the need to dig deep into past course books.

The externally benchmarked progress test to assess the performance of KSAU PharmD students was held in the middle of the second semester of the 2017-2018 academic year. The test was chosen because it was benchmarked, administrated to students at all academic levels, ie, professional years 1 through 4, and covered all learning 


\section{American Journal of Pharmaceutical Education 2019; 83 (9) Article 6237.}

domains. The number of questions allocated to each domain corresponds to its weigh in the PharmD curriculum, ie, 27 MCQs for pharmaceutical sciences and 73 MCQs for clinical pharmacy and pharmacy practice for a total of 100 MCQs.

The number of male and female students who sat for the test in the three programs and the average grades (\%) by academic level (P1-P4) are shown in Table 3. The average grade of KSAU PharmD students increased significantly from one academic level to the next and were significantly different between male (P1-P4) and female students (P1-P3) as no female students reached P4 in the professional program at KSAU-HS until the academic year 2018-2019. Additionally, the average grades were significantly higher for KSAU-HS PharmD students compared to grades of students from two KSA-based benchmarking programs in every academic level, for both male and female students.

The institutionally designed and distributed course evaluations were completed by 2,247 students from 13 different programs, $(43.8 \%$ by male students and $56.3 \%$ by female students) in the university during the academic year 2017-2018. For the same academic year, 69 male and 89 female students (P1-P3) evaluated 21 courses in the first semester, and 69 male and 84 female students (P1P3) evaluated 23 courses in the second semester, with average response rates of $92.3 \%$ and $90 \%$ for male and female students, respectively. Descriptive statistics for KSAU-HS PharmD students who completed surveys and survey results are presented in Tables 4 and 5. For the first semester courses, the overall course evaluation showed significant differences between male and female students with a $t=2.28$ and $p=.028$. Only, the overall course evaluation score by male students was significantly higher than the institutional average score by male students, 3.50 (.05), $p=.0001$. While for the second semester courses, the overall course evaluation showed significant difference between male and female students with a $t=2.94$ and $p=.005(p<.05)$. Additionally, the overall course evaluation by male and female students was significantly higher than the institutional male and female average scores, $3.43(.05), p=.0001(p<.05)$ and $3.38(.05)$,

Table 3. Progress Test Results of KSAU-HS Students Compared to Students From Two KSA-Based Benchmarking Programs

\begin{tabular}{|c|c|c|c|c|}
\hline Students & Academic Level & No. of Students & Grade $(\%)$ Mean (SD) & $p$-Value \\
\hline KSAU-HS PharmD & P1 & 35 & $37.37(6.17)$ & .0001 \\
\hline \multirow[t]{3}{*}{ Male Students } & P2 & 20 & $48.30(5.12)$ & \\
\hline & P3 & 11 & $49.36(7.27)$ & \\
\hline & P4 & 14 & $55.71(8.67)$ & \\
\hline KSAU-HS PharmD & P1 & 31 & $39.13(5.25)$ & .0001 \\
\hline \multirow[t]{2}{*}{ Female Students } & P2 & 27 & $52.78(6.85)$ & \\
\hline & P3 & 25 & $54.04(6.83)$ & \\
\hline P1 Male Students vs. & $\mathrm{COP}$ & 35 & $37.37(6.17)$ & \\
\hline Benchmark 1 & B1 & 15 & $29.60(6.93)$ & .0001 \\
\hline Benchmark 2 & B2 & 24 & $32.71(5.98)$ & .006 \\
\hline P1 Female Students vs. & $\mathrm{COP}$ & 31 & $39.13(4.25)$ & \\
\hline Benchmark 1 & B1 & 31 & $29.32(5.23)$ & .0001 \\
\hline Benchmark 2 & B2 & 56 & $35.18(4.81)$ & .0001 \\
\hline P2 Male Students vs. & $\mathrm{COP}$ & 20 & $48.30(5.12)$ & \\
\hline Benchmark 1 & B1 & 37 & $37.73(7.52)$ & .0001 \\
\hline Benchmark 2 & B2 & 19 & $37.58(7.12)$ & .0001 \\
\hline P2 Female Students vs. & $\mathrm{COP}$ & 27 & $52.78(6.85)$ & \\
\hline Benchmark 1 & B1 & 37 & $34.70(8.45)$ & .0001 \\
\hline Benchmark 2 & B2 & 25 & $42.80(6.01)$ & .0001 \\
\hline P3 Male Students vs. & $\mathrm{COP}$ & 11 & $49.36(7.27)$ & \\
\hline Benchmark 1 & B1 & 43 & $43.67(7.52)$ & .028 \\
\hline Benchmark 2 & B2 & 17 & $41.06(7.80)$ & .012 \\
\hline P3 Female Students vs. & $\mathrm{COP}$ & 25 & $54.04(6.83)$ & \\
\hline Benchmark 1 & B1 & 90 & $42.82(6.58)$ & .0001 \\
\hline Benchmark 2 & B2 & 52 & $46.65(7.91)$ & .0001 \\
\hline P4 Male Students vs. & $\mathrm{COP}$ & 14 & $55.71(8.67)$ & \\
\hline Benchmark 1 & B1 & 43 & $45.44(8.21)$ & .0001 \\
\hline Benchmark 2 & B2 & 30 & $46.83(8.88)$ & .006 \\
\hline
\end{tabular}


American Journal of Pharmaceutical Education 2019; 83 (9) Article 6237.

Table 4. Progress Test Results of KSAU-HS Students by Academic Level

\begin{tabular}{lllcc}
\hline Academic Level & & Gender & No. of Students & Response Rate (\%) \\
\hline First Semester & P1 & Male & 37 & 100 \\
& & Female & $29-33$ & $88-100$ \\
& P2 & Male & 19 & 95 \\
& & Female & $30-33$ & $91-100$ \\
& P3 & Male & 13 & 93 \\
Second Semester & Female & Male & $22-23$ & $88-92$ \\
& P1 & Female & 37 & 100.00 \\
& Male & Female & $29-33$ & $88-100$ \\
& Male & $16-19$ & $80-95$ \\
& P3 & Female & 30 & 91 \\
& & 13 & 93 \\
\end{tabular}

$p=.0001(p<.05)$, respectively. The graphical depiction of the results is seen in Figure 1.

\section{DISCUSSION}

The push for a certain level of international collaboration between colleges of pharmacy seems to be more common now than decades ago. Two unpublished surveys conducted by Samford University and the University of Illinois in 2007 and 2010, respectively, to which 63 US colleges responded, showed that $62 \%$ (39) has active global or international programs and of these, 29 colleges had formal agreements with foreign institutions. ${ }^{7}$ The Accreditation Council for Pharmacy Education (ACPE) also started to certify pharmacy professional degree programs outside the United States in 2012, in an effort to bring uniformity to curricular development. ${ }^{13}$ Almost simultaneously, the Global Alliance for Pharmacy Education (GAPE) agreed to promote the sharing of quality pharmacy education resources globally so that all parties can benefit from best practices wherever they are demonstrated. ${ }^{14}$

That colleges of pharmacy outside the United States seek to benefit from the experience of their American counterparts has been well documented. This fact is indirectly supported by the increase in readership of the American Journal of Pharmaceutical Education since it implemented open access, online publishing. ${ }^{15}$ The benefits of educational collaborative efforts between institutions range in scope from simple academic guidance and professional advice, to a full-fledged exchange of students, resources, and faculty members, as well as research collaboration, with or without financial commitments. In the collaborative agreement between the KSAU-HS College of Pharmacy and the University of Tennessee College of Pharmacy, the major advantage has been the ability to use the curriculum of an

Table 5. Progress Test Results of KSAU-HS Students Compared by Gender

\begin{tabular}{|c|c|c|c|}
\hline Survey Domain & & Gender & Rating out 5 Mean (SD) \\
\hline \multirow[t]{6}{*}{ First Semester } & \multirow[t]{2}{*}{ The beginning of the course (Preparation) } & Male & $3.69(0.26)$ \\
\hline & & Female & $3.58(0.32)$ \\
\hline & What happened during the course (Delivery) & Female & $3.43(0.32)$ \\
\hline & \multirow[t]{2}{*}{ Perceived impact on student development } & Male & $3.61(0.32)$ \\
\hline & & Female & $3.50(0.35)$ \\
\hline & Overall course evaluation & Female & $3.45(0.16)$ \\
\hline \multirow[t]{5}{*}{ Second Semester } & \multirow[t]{2}{*}{ The beginning of the course (Preparation) } & Male & $3.78(0.20)$ \\
\hline & & Female & $3.75(0.30)$ \\
\hline & \multirow[t]{2}{*}{ What happened during the course (Delivery) } & Male & $3.80(0.20)$ \\
\hline & & Female & $3.53(0.29)$ \\
\hline & Perceived impact on student development & Male & $3.85(0.21)$ \\
\hline
\end{tabular}




\section{American Journal of Pharmaceutical Education 2019; 83 (9) Article 6237.}

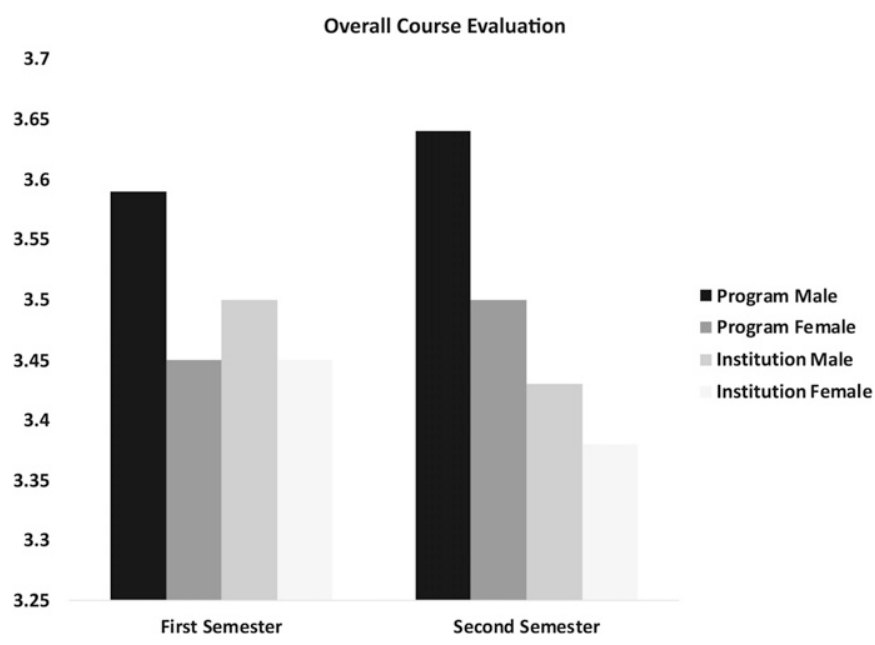

Figure 1. Average Evaluation Rating Out of 5 for the Overall Course Evaluation in the Course Evaluation Survey

ACPE-accredited program, thereby giving the limited number of faculty members in a new college the opportunity to build up its physical and academic infrastructure.

Not allowing immediate course revisions or alterations to individual lectures in the first year of implementation, in effect, protected the integrity of the transferred curriculum. Thus, senior college leaders did not have to be concerned about major omissions and/or additions that may have resulted in misalignments or weaknesses in the curriculum. Nevertheless, KSAU-HS College of Pharmacy faculty members had to create new courses either because of licensing limitations that prevented the transfer of some curricular elements, such as the course on immunizations, or because of the need to adapt some courses to the local environment, such as was the case with IPPEs and with a course on pharmacy law. Like IPPEs, the curriculum for APPEs was not included in the agreement and were instead designed at KSAU-HS College of Pharmacy to take into consideration the tight integration between the college and MNG-HA hospitals. A new course, the PharmD research course, was introduced as an initiative by College of Pharmacy leaders to stress the value of supervised student research in producing well-rounded, modern clinical pharmacists to fulfill the country's needs. Another course that was introduced, the seminar, is intended to further students' communication skills in evidence-based presentations. For all of these courses and experiences, complete course books with general learning outcomes, lecture/sessions learning outcomes, assessment tools and methodology, grading criteria and required reading material were also developed. In most of the courses in the PharmD study plan, students are subjected to continuous assessment, with a final examination administered at the end of every semester. Furthermore, P1-P4 students sit for a progress test that is administered annually. Assessment of IPPEs and APPEs is usually performed using special rubrics and forms, as well as by review of student portfolios. For APPEs, students must pass each rotation to pass the internship year.

In addition to highly qualified, mostly Westerneducated faculty members and an affiliation with one of the largest tertiary health care systems in Saudi Arabia, the College of Pharmacy at KSAU-HS has a robust monitoring system for teaching and learning. The college home is a new state of the art building that has classrooms and laboratories that are equipped with advanced educational technology, laboratory equipment, and clinical simulation tools, such as smart mannequins. Administratively, college and department councils play their classic roles in facilitating student teaching and learning. Additionally, the college has an Academic Affairs Department managed by the Associate Dean for Student and Academic Affairs, who also chairs the Curriculum, Assessment, and Student Progress Committees. The same department oversees the Assessment Unit, which manages all assessment tools used in the college of pharmacy learning and teaching experiences and the Student Affairs Department that deals with the day-to-day issue of student attendance and follow up, and offers assistance when needed. Each course has a coordination team to guarantee the suitability of the teaching material and assessment tools and items for attaining the learning outcomes for the course and the equity of experiences among different sections of the same course. Furthermore, the college has an academic mentorship program and participation is mandatory for all students, although attention is more focused on students with low academic achievement. These teams and programs are part of a larger system that includes the KSAU Education Affairs, Supporting Services, Deanship of Students, Deanship of Registration and Admission, Deanship of Library, and the Well Student Center, which offers psychological and social counseling. At the end of each academic year, the Student Progress and Promotion Committee reports on retention rates which is calculated by dividing the number of students who will be promoted to the next professional year from the total number of students who started in the current year.

Perhaps the most viable proof of the success of the implemented PharmD curriculum comes from student performance on the benchmarked progress test, which assesses the learning of KSAU-HS PharmD students from P1 through P4. The higher performance by students in the new KSAU-HS College of Pharmacy than that of students at two nationally and internationally accredited programs 


\section{American Journal of Pharmaceutical Education 2019; 83 (9) Article 6237.}

indicates a higher level of learning. Administering the North American Pharmacist Licensure Examination (NAPLEX) to our students would have been ideal to assess student learning; however, our request for our students to take the test was declined.

An indirect assessment of student learning comes from students' evaluations of courses in P1-P3. In 20172018, male PharmD students at KSAU-HS gave their courses in the first and second semesters significantly higher satisfaction ratings than the average institutional course satisfaction ratings. This was also the case for female PharmD students' satisfaction ratings of their second semesters courses. Although, the lower overall rating of courses by female students are consistent with the average institutional KSAU-HS course satisfaction rating, this result is difficult to explain. Most of the studies of gender bias in the evaluation of teaching are performed in non-segregated models of education, while teaching in this program is segregated by gender for students. Nevertheless, there is evidence in the literature that male instructors are perceived by male and female students to have better educational skills and were given higher evaluation scores. ${ }^{16,17}$ This might affect course evaluation by female students as they are mainly taught by female instructors. We will investigate this observation further in the future.

During the implementation of the curriculum, the College of Pharmacy solicited feedback from students, teaching faculty, and course coordinators through survey tools for the purpose of sharing their learning and teaching experiences respectively. The generated set of recommendations for curricular change was discussed in the curriculum committee and approved by the College Council. The approved changes were implemented the next time the course was delivered.

\section{CONCLUSION}

The College of Pharmacy at King Saud Bin Abdulaziz Saudi University for Health Sciences was able to effectively implement an accredited ACPE curriculum in a timely manner, even while building its ACPE-guided infrastructure, and graduated our first class of students in May 2016. The college's strategic choices helped create an atmosphere of synergy throughout this collaborative effort. According to college enrollment plans of about 80100 students per year, graduates from our program will help to ease the notable shortage of pharmaceutical care practitioners in Saudi Arabia in the near future. The college submitted its first PharmD program accreditation application to the nationally recognized Saudi National Center for Academic Accreditation and Assessment
(NCAAA) in May 2018. The PharmD program at KSAUHS will continue to closely align itself with current and future ACPE standards and will be prepared and willing to seek ACPE accreditation whenever it becomes a possibility for non-American schools of pharmacy.

\section{REFERENCES}

1. The Saudi Food and Drug Authority in collaboration with the World Health Organization. Bawazir S. Saudi Arabia Pharmaceutical Country Profile. http:/www.who.int/medicines/areas/coordination/ Saudi_ArabiaPSCP_Narrative2012-04-18_Final.pdf. Accessed October 1, 2016.

2. Spero JC, Grosso CD, Fraher EP. Pharmacists in North Carolina: Steady Numbers, Changing Roles: Cecil G. Sheps Center for Health Services Research, The University of North Carolina at Chapel Hill; 2014.

3. Albekairy AM, Khalidi N, Alkatheri AM, et al. Strategic initiatives to maintain pharmaceutical care and clinical pharmacists sufficiency in Saudi Arabia. SAGE Open Medicine.

2015;3:2050312115594816.

4. Kehrer JP, Schindel TJ, Mann HJ. Cooperation in pharmacy education in Canada and the United States. Am J Pharm Educ. 2010;74(8):Article 142.

5. Cisneros RM, Jawaid SP, Kendall DA, et al. International practice experiences in pharmacy education. Am J Pharm Educ.

2013;77(9): Article 188.

6. Gums JG. Changing the direction of clinical pharmacy outside the United States: time to step up. Pharmacotherapy. 2013;33(2):122-125.

7. Audus KL, Moreton JE, Normann SA, et al. Going global: the report of the 2009-2010 Research and Graduate Affairs Committee. Am J Pharm Educ. 2010;74(10):Article S8.

8. Anderson C, Bates I, Brock T, et al. Highlights from the FIPEd global education report. Am J Pharm Educ. 2014;78(1):Article 4. 9. Anderson C, Bates I, Beck D, et al. The WHO UNESCO FIP pharmacy education taskforce: enabling concerted and collective global action. Am J Pharm Educ. 2008;72(6):Article 127.

10. Fielding DW, Brazeau GA, Wasan KM. Introduction to the international pharmacy education supplement. Am J Pharm Educ. 2008;72(6):Article 126.

11. Kheir N, Zaidan M, Younes H, El Hajj M, Wilbur K, Jewesson PJ. Pharmacy education and practice in 13 Middle Eastern countries. Am J Pharm Educ. 2008;72(6):Article 133.

12. Al Ghazzawi WF, Abuzaid A, Al-Shareef OA, Al-Sayagh SM. Female pharmacists' career perceptions in Saudi Arabia: a survey at an academic center in Jeddah. Curr Pharm Teach Learn. 2017;9(6):1022-1030.

13. Accreditation Council for Pharmacy Education. International quality criteria for certification of professional degree programs in pharmacy. https://www.acpe-accredit.org/pdf/ISP/

QualityCriteria.pdf. Accessed October 1, 2016.

14. Prescott GM, Vu BN, Alsharif NZ, Prescott WA. Global health education in doctor of pharmacy programs in the United States. Am J Pharm Educ. 2017;81(2):Article 28.

15. DiPiro JT. Our international connections. Am J Pharm Educ. 2006;70(3):Article 61.

16. Boring A. Gender biases in student evaluations of teaching. $J$ Public Econ. 2017;145:27-41.

17. Mitchell KMW, Martin J. Gender bias in student evaluations. PS: Political Science and Politics. 2018;51(3):648-652. 
American Journal of Pharmaceutical Education 2019; 83 (9) Article 6237.

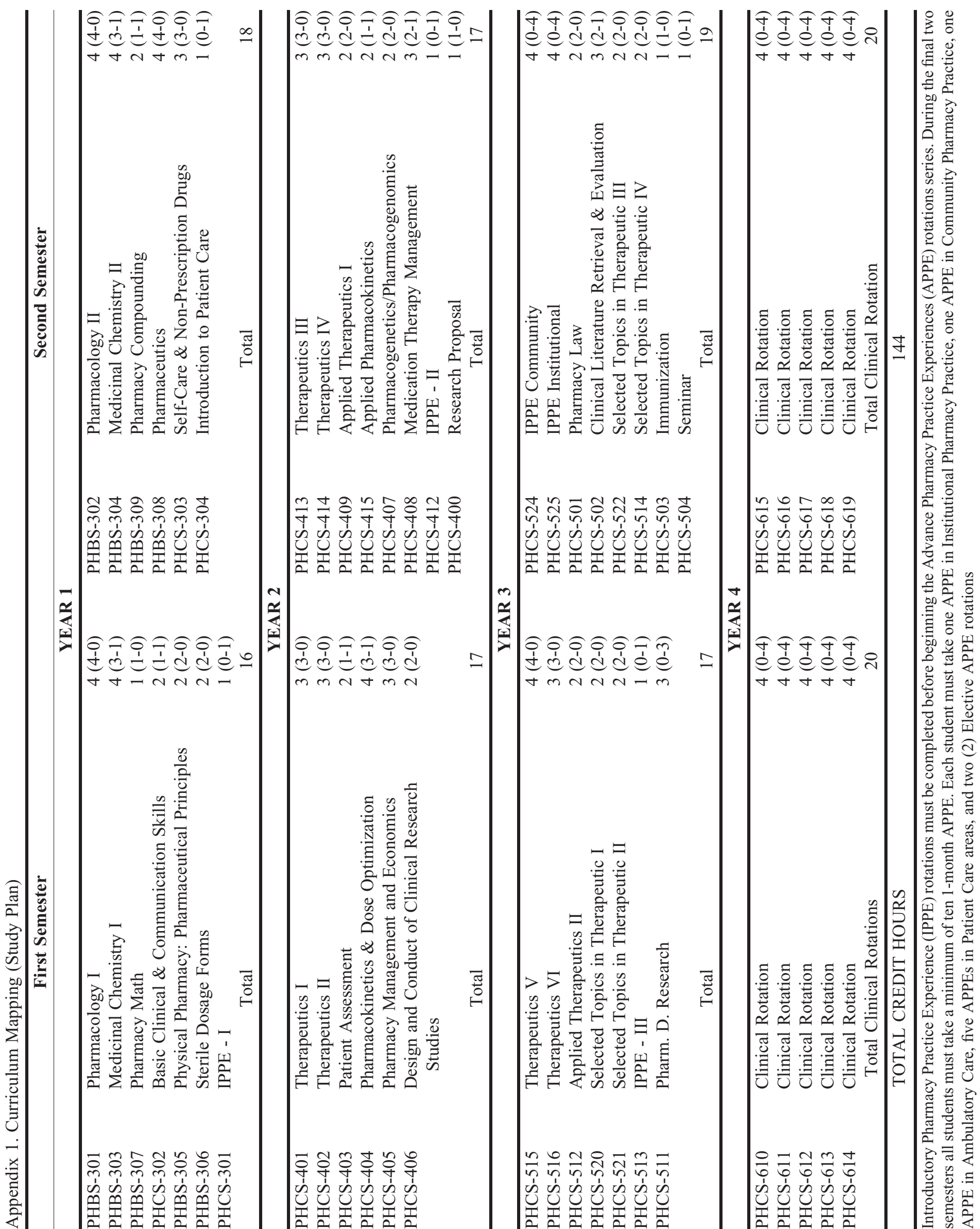


American Journal of Pharmaceutical Education 2019; 83 (9) Article 6237.

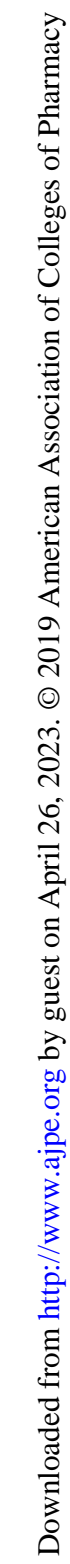

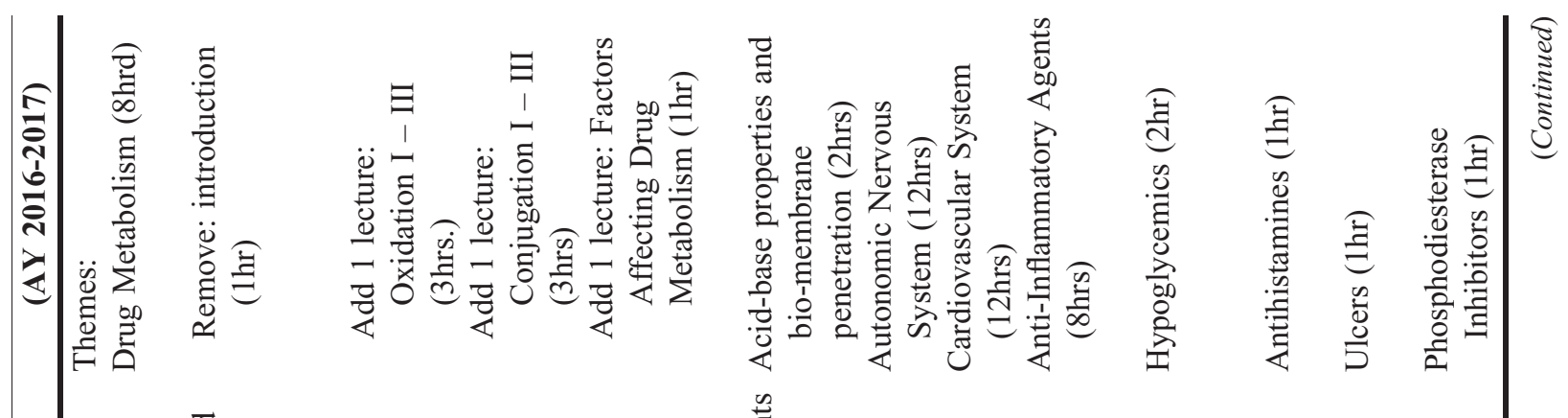

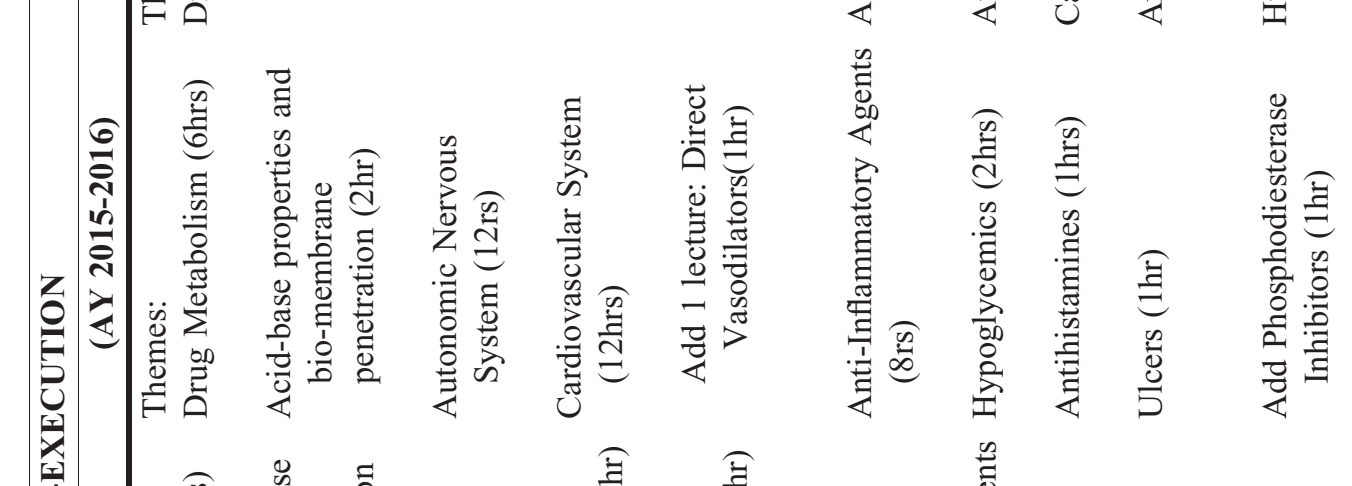

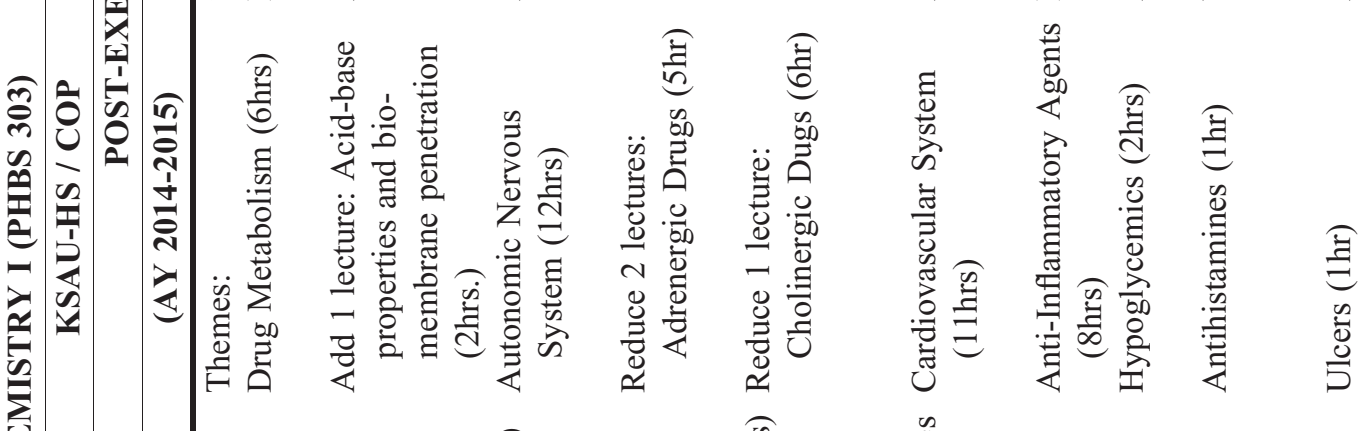

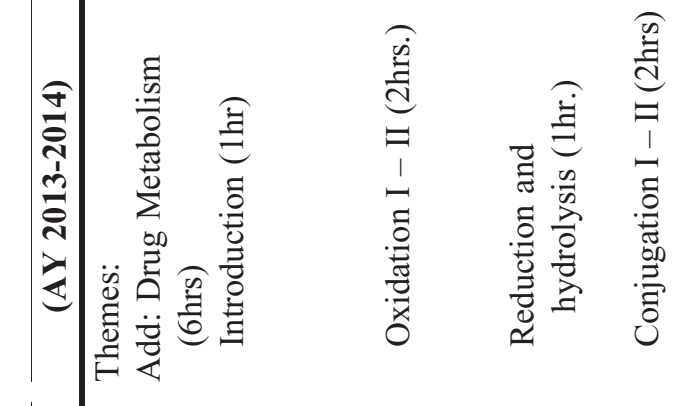

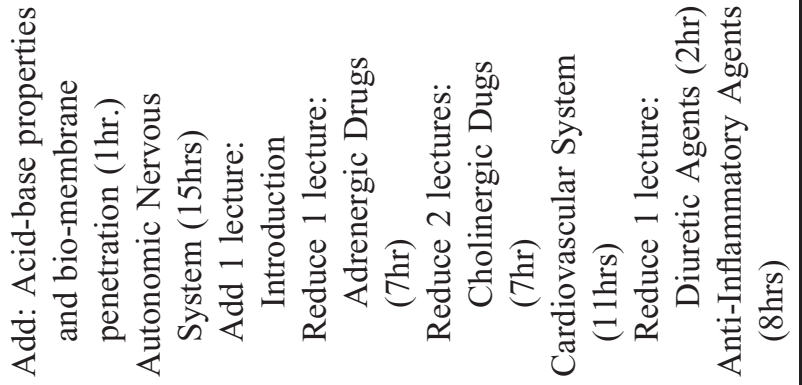

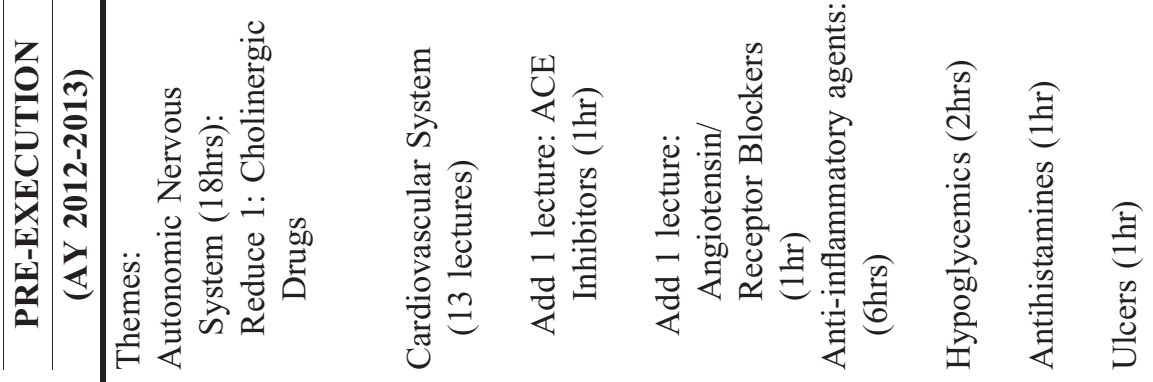

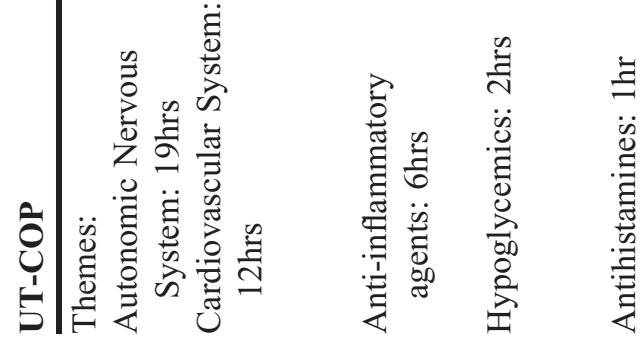

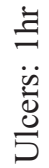


American Journal of Pharmaceutical Education 2019; 83 (9) Article 6237.

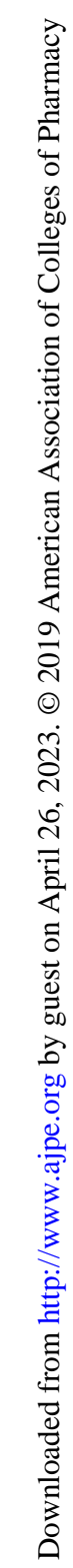

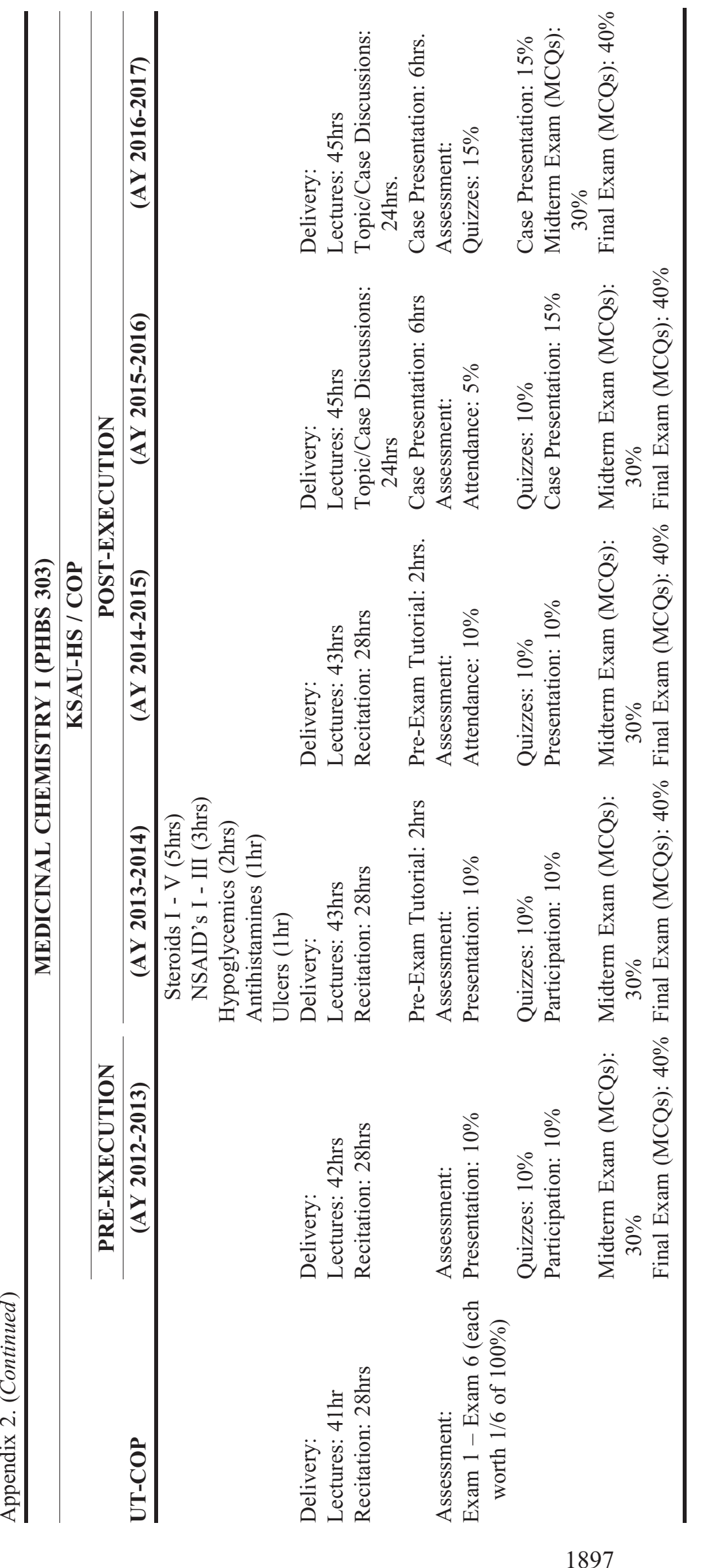

